\title{
Ascending aortic pseudoaneurysm after aortic valve replacement: Watch the tip of the cardioplegia cannula!
}

\author{
Abbas Emaminia, MD, ${ }^{\mathrm{a}}$ Ahmad Ali Amirghofran, MD, ${ }^{\mathrm{a}}$ Masih Shafa, MD, ${ }^{\mathrm{a}}$ Alireza Moaref, MD, ${ }^{\mathrm{a}}$ and Ramin Javan, MD, \\ Shiraz, Iran, and Charlottesville, Va
}

Ascending aortic pseudoaneurysms are rare and occur infrequently from anastomotic dehiscence of suture lines and cannulation sites from previous aortic surgery. ${ }^{1}$ Open surgical approach is the management of choice but carries a high risk of pseudoaneurysm rupture at the time of sternotomy. We describe a case of ascending aortic pesudoaneurysm with the orifice located on the posterior wall of the aorta, which is caused by the tip of the cardioplegia cannula inserted during a previous cardiac operation.

\section{CLINICAL SUMMARY}

A 23-year-old woman with endocarditis of the mitral and aortic valves underwent double valve replacement surgery at an outside hospital. Fever developed early after surgery and was attributed to confirmed arthritis of the right ankle. Transthoracic and transesophageal echocardiography on the second postoperative week showed a $2 \times 2-\mathrm{cm}$ mass located between the aorta and the pulmonary artery, consistent with pseudoaneurysm and infection. Intravenous antibiotics were continued for 2 more weeks. Serial echocardiography failed to show any shrinkage in the mass size, and the computed tomographic scan revealed an increase in size to $4 \times$ $4.5 \mathrm{~cm}$, with mass effect on the aorta and the pulmonary artery (Figure 1). Neither transthoracic nor transesophageal echocardiography showed any flow inside the mass. The patient was referred to our institution, where a decision was made to take her to the operating room with the impression of aortic root pseudoaneurysm versus abscess.

Owing to retrosternal adhesion and approximation of the aorta to the sternum as a result of the mass effect, the right common femoral artery was cannulated. After full heparinization, blood was drained to the oxygenator reservoir and the heart was emptied for 90 seconds. Blood was then returned to the heart after uneventful sternotomy. Adhesions were then released off-pump. Right atrial access was then secured, cardiopulmonary bypass initiated, and the mass was approached. It was filled with a clot. The aorta was clamped,

\footnotetext{
From the Division of Cardiovascular Surgery, Department of Surgery, Faghihi Hospi-

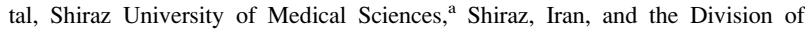
Thoracic and Cardiovascular Surgery, Department of Surgery, University of Virginia, ${ }^{\mathrm{b}}$ Charlottesville, Va.

Received for publication March 26, 2008; accepted for publication April 13, 2008.

Address for reprints: Abbas Emaminia, MD, Division of Cardiac Surgery, Department of Surgery, Faghihi Hospital, Shiraz University of Medical Sciences, Shiraz, Iran (E-mail: emaminia@gmail.com)

J Thorac Cardiovasc Surg 2009;137:1285-6

$0022-5223 / \$ 36.00$

Copyright (C) 2009 by The American Association for Thoracic Surgery

doi:10.1016/j.jtcvs.2008.04.006
}

cardioplegic solution was administered, and without cooling the patient, the aorta was opened. We found a 4-mm hole with well-defined borders on the posterior wall of the aorta, directly opposite the point of previous cannulation for infusion of cardioplegic solution (Figure 2). The orifice was closed with 4-0 Prolene suture (Ethicon, Inc, Somerville, NJ) reinforced by Teflon pledgets. The mechanical valve appeared to be functioning normally and was left in place. The aortotomy was closed and the patient was weaned from cardiopulmonary bypass uneventfully. The postoperative course was uncomplicated and no infectious organism was found from clots or the surrounding tissues.

\section{DISCUSSION}

Previous cardiac surgery is the most frequent cause of aortic pseudoaneurysms ${ }^{1}$; even so, pseudoaneurysm occurs in less than $0.5 \%$ of all cardiac surgical cases. ${ }^{2}$

The surgical management of ascending aortic pseudoaneurysms remains a challenge. Authors report a mortality rate ranging from $29 \%$ to $46 \%$, most frequently as a consequence of fatal hemorrhage resulting from rupture of the pseudoaneurysm during sternal re-entry or surgical maneuvers for its repair. ${ }^{1}$ Median sternotomy with the use of femorofemoral bypass and hypothermic circulatory arrest has been the strategy of choice. ${ }^{2}$

The keystones of successful treatment are preventing cardiac injury during the opening of the chest, with consequent exsanguination, as well as protecting the brain. ${ }^{3}$

Our strategy to safely reopen the chest in patients with moderate risk, similar to this case, is to drain the blood into the oxygenator reservoir for 1 to 2 minutes to have an empty, relatively collapsed heart and aorta. We then return the blood to the circulation after the sternum is opened. Adhesions are then released, with no need to be on the pump. Another advantage of this technique is that the majority of the patient's blood volume is saved in the reservoir, and less blood may be lost in case a catastrophic event happens at the time of sternotomy.

There are several reports in the literature describing cases of ascending aortic pseudoaneurysms with the sac located anteriorly. To the best of our knowledge, this may be the first report of such a defect, in the posterior wall of the aorta, caused by the tip of the cannula for cardioplegic infusion. It is very unlikely that the tip of the cardioplegia cannula will perforate the posterior wall of the aorta in adult patients, but care should be taken not to advance the cannula too aggressively and also to look for any injuries in patients whose aortas are opened. 


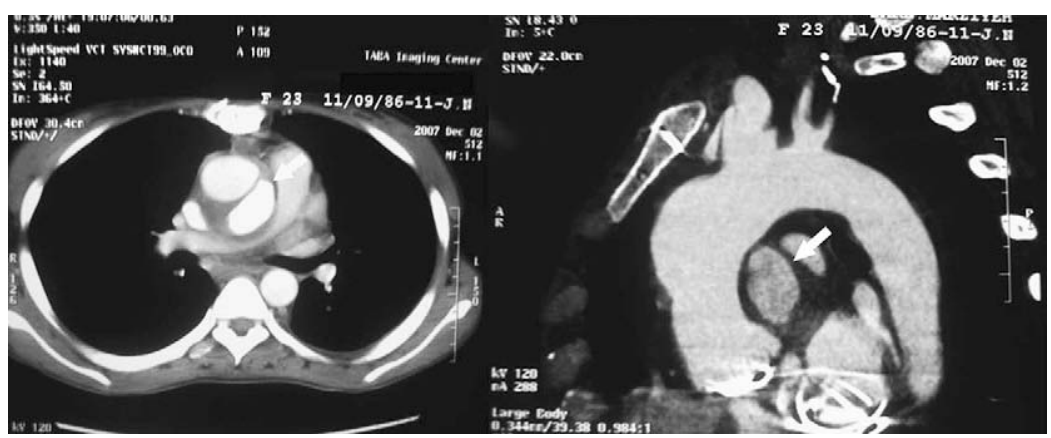

FIGURE 1. Computed tomographic (CT) scan showing the retroaortic mass (white arrow) with the mass effect on the pulmonary artery and aorta. No connection between the mass and aorta is identifiable.

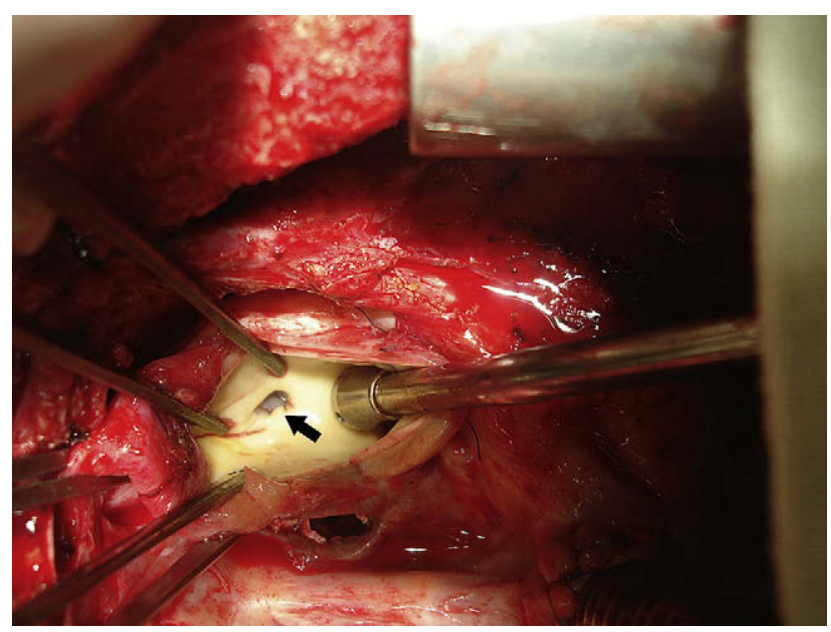

FIGURE 2. Intraoperative image showing a well-defined 4-mm hole in the posterior wall of the aorta (arrow). No sign of inflammation or necrosis is detectable.
In conclusion, we describe a case of ascending aortic pseudoaneurysm on the posterior wall of the aorta most probably caused by the tip of the cardioplegia cannula. It is recommended that extra precautions be taken while the tip of the cannula is being placed and that the aortic wall be inspected carefully before the aortotomy incision is closed.

\section{References}

1. Sullivan KL, Steiner RM, Smullens SN, Griska L, Meister SG. Pesudoaneurysm of the ascending aorta following cardiac surgery. Chest. 1998;93:138-43.

2. Katsumata T, Moorjani N, Vaccari G, Westaby S. Mediastinal false aneurysm after thoracic aortic surgery. Ann Thorac Surg. 2000;70:547-52.

3. Atik FA, Navia JL, Svensson LG, Vega PR, Feng J, Brizzio ME, et al. Surgical treatment of pseudoaneurysm of the thoracic aorta. J Thorac Cardiovasc Surg. 2006;132:379-85.

\section{Dual left ventricular restorations in a patient with cardiac sarcoidosis}

Takeshi Shimamoto, MD, ${ }^{\mathrm{a}}$ Takeshi Nishina, MD, PhD, ${ }^{\mathrm{a}}$ Akira Marui, MD, PhD, ${ }^{\mathrm{a}}$ and Masashi Komeda, MD, PhD, ${ }^{\mathrm{a}, \mathrm{b}, \mathrm{c}}$

Kyoto, Toyohashi, and Yamato, Japan

From the Department of Cardiovascular Surgery, Kyoto University Graduate School of Medicine, ${ }^{a}$ Kyoto, the Department of Cardiovascular Surgery, Toyohashi Heart Center, ${ }^{\mathrm{b}}$ Toyohashi, and the Department of Cardiovascular Surgery, Yamato Seiwa Hospital, ${ }^{\mathrm{c}}$ Yamato, Japan.

Received for publication March 14, 2008; revisions received March 29, 2008; accepted for publication April 12, 2008.

Address for reprints: Takeshi Shimamoto, MD, Department of Cardiovascular Surgery, Kyoto University Graduate School of Medicine, 54 Shogoin Kawahara, Sakyo, Kyoto 606-8507, Japan (E-mail: shimamo@kuhp.kyoto-u.ac.jp).

J Thorac Cardiovasc Surg 2009;137:1286-8

$0022-5223 / \$ 36.00$

Copyright $\odot 2009$ by The American Association for Thoracic Surgery

doi:10.1016/j.jtcvs.2008.04.007

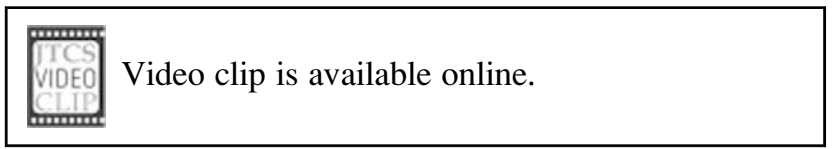

Surgical ventricular restoration (SVR) remains a challenge in cases of idiopathic dilated cardiomyopathy. It is even more challenging when multiple ventricular segments are affected and located near the base of the left ventricle (LV). Here, we report a case wherein dual SVRs were performed 